\title{
Two-step Biodiesel Production from Used Activated Bleaching Earth at Palm Oil Refining Plant
}

\author{
Teerasak Punvichai 1,* (D), Supranee Patisuwan 1(D), Viboon Pongkanpai ${ }^{1}{ }^{(\mathbb{D})}$, Prodpran Khamon ${ }^{1(\mathbb{D})}$ \\ 1 Faculty of Science and Industrial Technology, Prince of Songkla University, Suratthani campus, Suratthani, Thailand, \\ 84000; teerasak.punvichai@yahoo.com (T.P.); supraneepatisuwan@gmail.com (S.P.); pviboonprapai@ hotmail.com \\ (V.P.); prodpran.k@psu.ac.th (P.K.); \\ * Correspondence: teerasak.punvichai@yahoo.com; teerasak.p@psu.ac.th;
}

Scopus Author ID 16507462500

Received: 12.06.2020; Revised: 3.07.2020; Accepted: 3.07.2020; Published: 3.07.2020

\begin{abstract}
A study on two-step biodiesel production of agricultural by-products, namely palm oil derived using activated bleaching earth (UABE), collected from the Oleen Palm Oil industrial refining plant consisting of $22.4 \%$ of waste oil. This waste oil showed free fatty acid content and a saponification value of $15.5 \%$ and $199.7 \mathrm{mg} \mathrm{KOH} / \mathrm{g}$, respectively. The FFA content after esterification should be approximately $1.0 \%$, not only to save glycerol and the catalyst involved in the esterification but also to achieve high biodiesel conversion during the transesterification. An alkaline catalyst was successfully used to produce biodiesel in the second step. A 97.6\% conversion to biodiesel based on the European Standard EN 14214:2003 was achieved under the conditions (1.0\% NaOH catalyst relative to waste oil, the molar ratio of free fatty acid, and methanol of $1: 13.22,60^{\circ} \mathrm{C}, 1 \mathrm{~h}$ ). Overall, this novel two-step process achieved highly enhanced biodiesel conversion (74.6\% to $100.0 \%)$ with a significantly increased molar ratio of free fatty acid and methanol (1:2.71 to $1: 15.89)$ and catalyst requirements $(1.0 \%$ $\mathrm{NaOH})$.
\end{abstract}

Keywords: Used activated bleaching earth; Esterification; Transesterification; Biodiesel.

(C) 2020 by the authors. This article is an open-access article distributed under the terms and conditions of the Creative Commons Attribution (CC BY) license (https://creativecommons.org/licenses/by/4.0/).

\section{Introduction}

Crude palm oil is extracted from the fibrous mesocarp of the palm fruit (Elaeis guineensis). In the world's production of major vegetable oil, palm oil accounts for $16 \%$. The importance of oils and fats in meeting the ever-increasing population demand for food and nonfood products continues to grow. The growth in demand for vegetable oils is strongest in the developing nations of Asia [1]. During the past decade, palm oil's share of total vegetable oil production increased from $15 \%$ to about $21 \%$ [2]. Solid wastes from the crude palm oil refining industry constitute a significant source of low-grade organic compounds. The upgrading of crude oils from vegetable origin requires the use of absorbents for the removal of carotene, chlorophyll, and other components formed during the refining process, (e.g., phosphatides and soaps). Used activated bleaching earth (UABE) is one of the most commonly used of these absorbents due to its high absorption capacity [3-5]. Large amounts of UABE containing nearly $30 \%$ of its weight as waste oil are discarded every day, this is a substrate that should be utilized for the synthesis of a wide range of products to be used as bulk chemicals (Fig. 1) [4,5]. Furthermore, the recycling of waste oil, which amounts to 500,000 t per year in Japan alone, will also contribute to the alleviation of environmental problems [6]. If an effective treatment of oil contained in the $\mathrm{UABE}$ is available, remaining $\mathrm{UABE}$ can be recycled in the oil refinery 
process or may be used as a soil conditioner. Low valued oils from waste bleaching earth samples are potential substrates for biodiesel fuel production [3,7], biochemical, soap, and oleochemical products $[4,5]$. Therefore, there is a need for innovation.

Biodiesel conversion requires the use of a catalyst $[8,9]$. Alkali catalysts facilitate a high reaction rate and require much lower amounts of methanol and shorter reaction time than acid catalysts $[10,11]$. However, alkali catalysts cannot be used for feedstocks with a high content of free fatty acid (FFA), because it causes saponification of the FFAs. According to previous studies, lipids with FFA levels exceeding $0.5 \%$ [12,13], or 2.0\% [14] undergo marked saponification in the presence of alkaline ions. Another study reported that alkaline catalysts could be used when the FFA content is lower than 3.0\% [15]. Biodiesel was successfully produced using waste coffee grounds lipids, containing 1.9\% FFAs, under alkali catalysts [10]. Therefore, the FFA content threshold for the possible use of alkaline catalysts may be dependent on the type of feedstock and should be determined experimentally in each situation.

However, the issue that alkaline catalysts cannot be used for the production of biodiesel from the oil or lipids with more than $3.0 \%$ of FFA content needs to be addressed. Two-step processes have been developed for biodiesel production from feedstocks with high FFA content, such as waste cooking oil [16,17]. A typical two-step process comprises esterification of FFA with methanol, using an acid catalyst, and transesterification of glycerides and esters generated in the first step, using an alkaline catalyst (Fig. 2). However, the first esterification step requires a large amount of methanol and a long reaction time, and thus, the recovery of methanol from this reaction consumes both energy and time $[12,16]$. Recently, a novel twostep process comprised of esterification and transesterification steps has attracted attention as an alternative for the conventional two-step process $[15,18]$.

This study is aiming at two-step biodiesel production for value-adding of used activated bleaching earth (UABE) from palm oil refining plant at Oleen Co., Ltd.

\section{Materials and Methods}

\subsection{Analysis of lipids in $U A B C$.}

The sampled CPO and UABC were collected from Oleen Co., Ltd. and stored at below $4{ }^{\circ} \mathrm{C}$ to avoid rancidity. The percentage of crude oil of UABE was determined by the AOCS method Ba 3-38 [19]. Crude oil was obtained from UABE by double extraction with hexane $(1: 1 \mathrm{w} / \mathrm{v})$ in a $2,000 \mathrm{ml}$ flask. The mixture was shaken for $10 \mathrm{~min}$ at room temperature. The hexane layer was separated, and the crude oil concentrated in an evaporator. The crude oil and CPO were analyzed for free fatty acid (FFA) by AOCS Ca 5a-40 [19], saponification value by AOCS Cd 3-25 [19] and fatty acid composition was determined by gas chromatography AOCS Ce 1-62 [19].

\subsection{Biodiesel production by two-step esterification-transesterification.}

Biodiesel was produced from the waste oil of UABE from the palm oil refining plant at Oleen Co., Ltd., by a two-step transesterification method. In this, pre-treatment acid esterification followed by base-transesterification reactions were employed for biodiesel production. In the esterification process, the crude oil was mixed with methanol in the ratio of 4.5:1, 9:1, 13:1, and 18:1 (molar ratio). 98\% concentrated sulfuric acid (1\% v/v crude oil) was added as a catalyst to enhance the esterification reaction to the mixture. The mixture of crude oil, methanol, and the catalyst was allowed to react in the reactor at $60{ }^{\circ} \mathrm{C}$ for $1 \mathrm{~h}$ under the 
stirrer speed of $350 \mathrm{rpm}$ approximately. The reaction was stopped after $1 \mathrm{~h}$. The mixture obtained, consisting of two layers, the upper layer of methanol and sulfuric acid and the lower layer consisting of the esterified oil. With the help of separating funnel, the esterified oil was separated from the methanol and other impurities.

The transesterification reaction was carried out with a mixture of esterified oil and methanol in the ratio of $4: 1$ by volume in the reactor. $1 \%$ of sodium hydroxide by weight was added to the mixture of esterified oil and methanol. The reaction was allowed to take place at a temperature of $60{ }^{\circ} \mathrm{C}$ and stirrer speed of $350 \mathrm{rpm}$ for $1 \mathrm{~h}$. The upper layer of the methyl ester (biodiesel) was separated from the lower layer of methanol, including other impurities, with the help of separating funnel. This was then followed by the post-treatment processes. Finally, sodium sulfate was added to methyl ester to remove water vapors and then filtered with a filter paper.

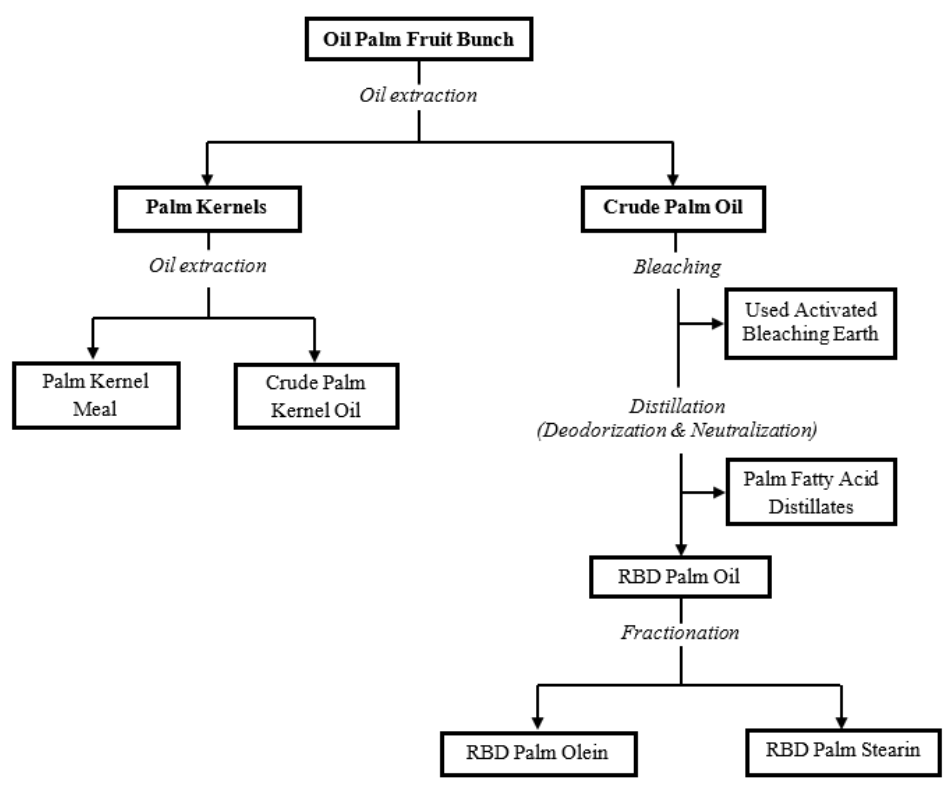

Figure 1. The production chain of crude palm oil and associated products and by-products (RBD: Refined bleached deodorized).

\begin{tabular}{|c|c|c|c|c|c|c|}
\hline $\mathrm{HOOCR}^{\prime}$ & + & $\mathrm{ROH}$ & Acid $\rightarrow$ & ROOCR' & + & $\mathrm{H}_{2} \mathrm{O}$ \\
\hline Free Fatty Acid & & Alcohol & & Biodiesel & & Water \\
\hline $\begin{array}{l}\mathrm{CH}_{2} \mathrm{OCO} \mathrm{R}^{\prime \prime \prime} \\
\mathrm{CHOCO} \mathrm{R"} \\
\mathrm{CHO} \\
\mathrm{CH}_{2} \mathrm{OCO} \mathrm{R}^{\prime}\end{array}$ & + & $3 \mathrm{ROH}$ & Base & $\begin{array}{l}\mathrm{CH}_{2} \mathrm{OH} \\
1 \\
\mathrm{CH}_{2} \mathrm{OH} \\
\mathrm{CH}_{2} \mathrm{OH}\end{array}$ & + & $\begin{array}{l}\text { R"'COOR } \\
\text { R"COOR } \\
\text { R'COOR }\end{array}$ \\
\hline Oil/Fat & & Alcohol & & Glycerin & & Biodiesel \\
\hline
\end{tabular}

Figure 2. Esterification (1) and Transesterification (2).

The reaction yield was measured as the fatty acid methyl ester (FAME) content by a TLC-FID analyzer (IATROSCAMTM MK-5, Iatron Laboratories Inc., Tokyo, Japan). Runs were done in triplicate. The significant difference between the means was determined using SPSS version 10.0 compare means one-way ANOVA. In all cases, statistical significance is $\mathrm{P}<0.05$. We calculated cost and benefit in terms of economics and environment return. 


\subsection{Percent conversion of esterification.}

Percent conversion was measured by total free fatty acid before esterification and after esterification.

Conversion $(\%)$

$$
=\quad \frac{(a-b)}{a} \times 100
$$

When; $\quad a=$ total free fatty acid before esterification

$\mathrm{b}=$ total free fatty acid after esterification

\subsection{Determination of FAME.}

Fifty microliters of the sample after transesterification were mixed with $50 \mu \mathrm{L}$ of chloroform, and the percentage of FAME was analyzed by a TLC-FID analyzer (IATROSCAMTM MK-5, Iatron Laboratories Inc., Tokyo, Japan).

\section{Results and Discussion}

\subsection{Composition of CPO and UABE.}

Table 1. Free fatty acid content and saponification value of UABE waste oil and CPO.

\begin{tabular}{l|c|c} 
Properties* & UABE Waste oil & CPO \\
\hline Free fatty acid (oleic acidity) (\%) & $15.5+0.4$ & $4.8+0.2$ \\
\hline Saponification value (mg KOH/g oil) & $199.7+1$ & $200.5+1$
\end{tabular}

Waste oil and CPO were analyzed for free fatty acid and saponification. Waste oil extracted from UABE by hexane and was $22.4 \pm 0.2 \%$. Acidity (free fatty acid content) and saponification values were $15.5 \pm 0.4 \%$ and $199.7 \pm 1.0 \mathrm{mg} \mathrm{KOH} / \mathrm{g}$ oil, and $4.8 \pm 0.2 \%$ and $200.5 \pm 1 \mathrm{mg} \mathrm{KOH} / \mathrm{g}$ oil for CPO and UABE waste oil respectively (Table 1). CPO was taken as a reference. The saponification value of UABE waste oil was higher than that of CPO, following the decrease of the triglyceride portion in samples, owing to the decrease of glycerol. Fatty acid compositions of samples are given in Table 2. CPO is confirmed as a source of saturated and monounsaturated fatty acids. However, low but significant amounts of trans fatty acid were found in waste oil, compared to CPO, as the probable result of hard thermal processing conditions applied.

Table 2. Fatty acid composition of UABE Waste oil and reference CPO [5].

\begin{tabular}{l|c|c|c|c|c}
\multirow{2}{*}{ Fatty acid } & \multicolumn{3}{c}{ UABE Waste oil } & \multicolumn{2}{c}{ CPO } \\
\cline { 2 - 5 } & $\mathbf{M w}$ & $\mathbf{( \% )}$ & $\mathbf{( m m o l e})$ & $\mathbf{( \% )}$ & $\mathbf{( m m o l e )}$ \\
\hline Saturated fatty acid & & $\mathbf{5 4 . 8}$ & & $\mathbf{4 8 . 0}$ & \\
\hline Lauric (C12:0) & 200 & 0.32 & 1.6 & 0.33 & 1.6 \\
\hline Myristic (C14:0) & 228 & 1.07 & 4.7 & 0.99 & 4.3 \\
\hline Palmitic (C16:0) & 256 & 47.45 & 185.0 & 41.49 & 162.1 \\
\hline Stearic (C18:0) & 284 & 5.08 & 17.9 & 4.49 & 15.8 \\
\hline Arachidic (C20:0) & 312 & 0.43 & 1.4 & 0.40 & 1.3 \\
\hline Behenic (C22:0) & 340 & 0.12 & 0.4 & 0.09 & 0.3 \\
\hline Other & 327 & 0.30 & 1.0 & 0.19 & 0.6 \\
\hline Monounsaturated fatty acid & & $\mathbf{3 7 . 7}$ & & $\mathbf{4 1 . 7}$ & \\
\hline Palmitoleic (C16:1 n-7c) & 254 & 0.12 & 0.5 & 0.17 & 0.6 \\
\hline Elaidic (C18:1 n-9t) & 282 & 2.95 & 10.5 & 0.11 & 0.4 \\
\hline Oleic (C18:1 n-9c) & 282 & 32.29 & 114.5 & 40.18 & 140.0 \\
\hline Eicosenoic (C20:1 n-9c) & 310 & 0.12 & 0.4 & 0.14 & 0.5 \\
\hline Other & 366 & 2.19 & 6.0 & 1.08 & 3.0
\end{tabular}




\begin{tabular}{l|l|l|c|c|c}
\multirow{2}{*}{ Fatty acid } & \multicolumn{2}{c|}{ UABE Waste oil } & \multicolumn{2}{c}{ CPO } \\
\cline { 2 - 6 } \multicolumn{1}{c|}{} & $\mathbf{M w}$ & $\mathbf{( \% )}$ & $\mathbf{( m m o l e )}$ & $\mathbf{( \% )}$ & $(\mathbf{m m o l e})$ \\
\hline Polyunsaturated fatty acid & & $\mathbf{7 . 5}$ & & $\mathbf{1 0 . 4}$ & \\
\hline Linoleic (C18:2 n-6cc) & 280 & 7.09 & 25.3 & 9.95 & 35.5 \\
\hline Linolenic (C18:3 n-3ccc) & 278 & 0.17 & 0.6 & 0.28 & 1.0 \\
\hline Other & 271 & 0.27 & 0.9 & 0.12 & 0.4 \\
\hline Total & & & 370.9 & & 369.9 \\
\hline Average Mw of fatty acid & & 271.0 & & 271.5 &
\end{tabular}

The analyzed fatty acid composition of the oils used in this study (Table 2) is consistent with published values. Waste oil and CPO contains high percentages of palmitic (16:0) and oleic (18:1) acids as major components. Waste oil and CPO, show a higher proportion of saturated fatty acids (54.8 and 48.0, respectively) compared to unsaturated fatty acids. But CPO contains less palmitic acid (41.49\%) than waste oil $(47.45 \%)$. CPO contains $41.7 \%$ of monounsaturated fatty acids, including $40.18 \%$ of oleic (18:1) acid. The percentage of oleic acid in waste oil is lower than in CPO, and the same applies to polyunsaturated fatty acids. Subsequently, waste oil had the highest proportion of trans fatty acid among the various oils used, probably because of the catalysis of isomerization by the activated clay or due to selective adsorptions [5].

\subsection{Biodiesel production from waste oil of $U A B E$.}

Biodiesel was produced from the waste oil of UABE from the palm oil refining plant at Oleen Co., Ltd., by a two-step transesterification method. Before applying the procedure exposed in section 2.2, the molecular weight of each by-product was computed based on the saponification value. The percentage of free fatty acid and the conversion of ester in the final products' first step esterification, waste oil UABE is shown in Table 3.

Table 3. Esterification of waste oil used activated bleaching earth with $1 \% \mathrm{H}_{2} \mathrm{SO}_{4}$ catalyzed at $60{ }^{\circ} \mathrm{C}$ for 60 minutes.

\begin{tabular}{c|c|c} 
Free fatty acid: Methanol (molar ratio) & Free fatty acid (\%) & Conversion (\%) \\
\hline $1: 4.5$ & $4.62 \pm 0.02^{\mathrm{a}}$ & $70.19^{\mathrm{d}}$ \\
\hline $1: 9$ & $3.46 \pm 0.01^{\mathrm{b}}$ & $77.68^{\mathrm{c}}$ \\
\hline $1: 13$ & $2.14 \pm 0.01^{\mathrm{c}}$ & $86.19^{\mathrm{b}}$ \\
\hline $1: 18$ & $1.07 \pm 0.01^{\mathrm{d}}$ & $93.09^{\mathrm{a}}$
\end{tabular}

a Values within the same column having the same or without superscript are not significantly different ( $>>0.05$ ); Data are written as mean value and standard deviation

It was found that the percentage conversion increased when increasing the molar ratio of free fatty acid and methanol (Table 3). This is the case, until a plateau at $\sim 93.09 \%$, for waste oil, with a free fatty acid of waste oil proportion in the range of $15.5+0.4$ to $1.07 \pm 0.01 \%$. However, we found a Linear graph for percentage conversion, namely waste oil of UABE, with a maximum at $\sim 15.5 \%$ of free fatty acid. The free fatty acid content decreases substantially to $\sim 1.07 \%$ of free fatty acid in the molar ratio of free fatty acid and methanol of $1: 18$. This shows the governing effect of the molar ratio of free fatty acid and methanol in these complex polyphasic media, due to the well-known physicochemical properties of the neoformed biodiesel. The aim of the first step is to decrease the FFA content as much as possible and to become an appropriate feedstock oil for the second step transesterification [20].

Waste oil and biodiesel in liquid phase after first step esterification free fatty acid $\sim 1.0$ $\%$ were continued to second step transesterification. Therefore, the balance of methanol and waste oil is important in solvent-free methanolysis. 
Table 4. Tranesterification of waste oil used activated bleaching earth with $1 \% \mathrm{NaOH}$ catalyzed at $60{ }^{\circ} \mathrm{C}$ for 60

\begin{tabular}{c|c} 
Oil : Methanol (molar ratio) & FAME (\%) \\
\hline $1: 2.71$ & $74.62 \pm 0.02^{\mathrm{f}}$ \\
\hline $1: 5.42$ & $83.46 \pm 0.01^{\mathrm{e}}$ \\
\hline $1: 7.97$ & $88.49 \pm 0.01^{\mathrm{d}}$ \\
\hline $1: 10.59$ & $94.76 \pm 0.01^{\mathrm{c}}$ \\
\hline $1: 13.22$ & $97.58 \pm 0.01^{\mathrm{b}}$ \\
\hline $1: 15.89$ & $100.00 \pm 0.00^{\mathrm{a}}$
\end{tabular}

a Values within the same column having the same or without superscript are not significantly different $(p>0.05)$; Data are written as mean value and standard deviation

To optimize the molar ratio of methanol to waste oil, the addition of methanol to the reaction mixture was investigated using molar ratios of methanol to waste oil from 1:2.71 to 1:15.89 (Table. 4). The theoretical molar ratio of methanol to waste oil is 1:3. When the ratio was $1: 2.71$, the FAME conversion was lower than $75 \%$, and when the ratio was $1: 5.42$, it was $83.46 \pm 0.01 \%$. This might be due to a diffusion limitation of methanol in the base-catalyzed transesterification on the waste oil of UABE. When the molar ratio was 1:13.22, the FAME conversion reached to $97.58 \pm 0.01 \%$ in a reaction time of $1 \mathrm{~h}$. The ester content could be reached more than $97 \%$ in comparison with the EN 14103 standard ( $96.5 \%$ min). However, in all cases of a methanol molar ratio, the conversion of waste oil to FAME increased and was higher than $70 \%$. The two-step reaction can be applied to any feedstock oils, especially in the case of high FFA content feedstock oils. If the FFA content is more than $2 \mathrm{wt} \%$ then the first step esterification will be followed by the second step transesterification [20,21].

\subsection{The quality of biodiesel waste oil UABE.}

In Europe, the quality of biodiesel is assessed under the provisions and the requirements of quality standard EN 14214 that should be met from each biodiesel sample so as to be a suitable substitute fossil diesel in the transport sector. Quality control was performed for the biodiesel produced under the optimum process conditions specified above (i.e., molar ratio 1:18 for the esterification and 1:13.22 transesterification step, respectively), based on the European Standard EN 14214:2003. Density at $15{ }^{\circ} \mathrm{C}$, acidity number, methyl ester content, the content of monoglycerides (MGs), diglycerides (DGs), and TGs and total and free glycerol, were determined and measured (Table 5). It should be noted that for further scaling up of biodiesel production and its promotion in the market, all quality characteristics specified by the European standard EN 14214 should be determined.

Table 5. The quality of biodiesel waste oil UABE.

\begin{tabular}{c|c|c}
\multicolumn{1}{c}{ Properties } & Biodiesel waste oil UABE & Limits \\
\hline Methyl ester content, \% & 97.58 & $>96.5$ \\
\hline Density at $15^{\circ} \mathrm{C}, \mathrm{kg} / \mathrm{m}^{3}$ & 875 & $860-900$ \\
\hline Monoglyceride content, $\%$ & 0.015 & $<0.8$ \\
\hline Diglyceride content, $\%$ & 0.001 & $<0.2$ \\
\hline Triglyceride content, \% & 0.004 & $<0.2$ \\
\hline Free glycerol, $\%$ & 0.003 & $<0.02$ \\
\hline Total glycerol, $\%$ & 0.007 & $<0.25$ \\
\hline Acid value, $\mathrm{mg} \mathrm{KOH} / \mathrm{g}$ & 0.38 & $<0.5$
\end{tabular}

\section{Conclusions}

Waste oil makes $22.4 \%$ on a dry weight basis of the sampled UABE, making this byproduct a suitable starting feedstock for biodiesel manufacture. Together with waste oil extraction from it was analyzed for free fatty acid content and saponification value fall and 
were in the range of expected values. The high acidity of these by-products (15.5\%) makes them peculiar feedstocks for the purpose, possibly leading to low glycerol content of the resulting biodiesels. This should allow the manufacture of biodiesel under conditions suitable to meet a set of physical properties of the end product. It was possible to achieve a FAME content of $74.62 \pm 0.02,83.46 \pm 0.01,88.49 \pm 0.01,94.76 \pm 0.01,97.58 \pm 0.01$ and $100.0 \pm 0.0 \%$ respectively for waste oil extracted from UABE (optimum the molar ratio of free fatty acid and methanol 1:2.71 to 1:15.89 of starting product respectively). The FAME content was maximized to $100 \%$ in the case of $1: 15.89$ ratio.

In this study, we successfully produced biodiesel from waste oil UABE with high FFA content. The two-step process could be applied to various non-edible and sustainable feedstocks with high FFA content. However, there are issues to be addressed: the glycerol should be recycled from the transesterification to the esterification step. Thus, the above study shows an innovative way for co-valorizing important by-products of palm oil processing, with an added value coming from the mixture of these low-cost by-products.

\section{Funding}

This research was funded by Prince of Songkla University.

\section{Acknowledgments}

This work was financially supported by Prince of Songkla University, Suratthani campus. Authors wish to thank for Oleen Palm Oil plant (Samutsakorn, Thailand) for kindly providing the samples of palm oil and by-products.

\section{Conflicts of Interest}

The authors declare no conflict of interest.

\section{References}

1. Drewnowski, A.; Popkin, B.M. The Nutrition Transition: New Trends in the Global Diet. J. Nutr. Rev. 1997, 55, 31-43, https://doi.org/10.1111/j.1753-4887.1997.tb01593.x.

2. Chandrasekharan, N.; Yusof, B. Palm oil in human nutrition and health. J. Plant. 2000, 76, 299-312.

3. Lara, P.V.; Park, E.Y. Potential application of waste activated bleaching earth on the production of fatty acid alkyl esters using Candida cylindracea lipase in organic solvent system. J. Enzyme. Microb. Technol. 2004, 34, 270-277, https://doi.org/10.1016/j.enzmictec.2003.10.015.

4. Punvichai, T.; Pioch, D. Co-valorization of agro-industry by-products: effect of citrus oil on the quality of soap derived from palm fatty acid distillate and spent bleaching clay. Lett. Appl. NanoBioScience. 2019, 8 , 571 - 575, https://doi.org/10.33263/LIANBS83.571575.

5. Punvichai, T.; Pioch, D. Covalorization of Palm Oil-Refining by-Products as Soaps. J. Am. Oil. Chem. Soc. 2019, 96, 329-336, https://doi.org/10.1002/aocs.12193.

6. Samukawa, T.; Kaieda, M.; Matsumoto, T.; Ban, K.; Kondo, A.; Shimada, Y.; Noda, H.; Fukuda, H. Pretreatment of immobilized Candida antarctica lipase for biodiesel fuel production from plant oil. J. Biosci. Bioeng. 2000, 90, 180-183, https://doi.org/10.1016/S1389-1723(00)80107-3.

7. Park, E.Y.; Sato, M.; Kojima, S. Lipase-catalyzed biodiesel production from waste activated bleaching earth as raw material in a pilot plant. Bioresour. Technol. 2008, 99, 3130-3135, https://doi.org/10.1016/j.biortech.2007.05.059.

8. Supaporn, P.; Yeom, S.H. Optimization of a two-step biodiesel production process comprised of lipid extraction from blended sewage sludge and subsequent lipid transesterification. $J$. Biotechnol. Bioprocess Eng. 2016, 21, 551-560, https://doi.org/10.1007/s12257-016-0188-3.

9. Amin, T.K.; Amin, N.A.S.; Hossein, M. A review on novel processes of biodiesel production from waste cooking oil. J. Appl. Energy 2013, 104, 683-710, https://doi.org/10.1016/j.apenergy.2012.11.061. 
10. Go, W.G.; Yeom, S.H. Statistical analysis and optimization of biodiesel production from waste coffee grounds by a two-step process. J. Biotechnol. Bioprocess Eng. 2017, 22, 440-449, https://doi.org/10.1007/s12257-017-0163-7.

11. Huang, G.H.; Chen, F.; Wei, D.; Zhang, X.W.; Chen, G. Biodiesel production by microalgal biotechnology. J. Appl Energy 2010, 87, 38-46, https://doi.org/10.1016/j.apenergy.2009.06.016.

12. Zullaikah, S.; Lai, C.C.; Vali, S.R.; Ju, Y.H. A two-step acid-catalyzed process for the production of biodiesel from rice bran oil. J. Bioresour. Technol. 2005, 96, 1889-1896, https://doi.org/10.1016/j.biortech.2005.01.028.

13. Phan, A.N.; Phan, T.M. Biodiesel production from waste cooking oils. J. Fuel 2008, 87, 3490-3496, https://doi.org/10.1016/j.fuel.2008.07.008.

14. Lam, M.K.; Lee, K.T.; Mohamed, A.R. Homogeneous, heterogeneous and enzymatic catalysis for transesterification of high free fatty acid oil (waste cooking oil) to biodiesel: A review. J. Biotechnol. Adv. 2010, 28, 500-518, https://doi.org/10.1016/j.biotechadv.2010.03.002.

15. Kombe, G.G.; Temu, A.K.; Rajabu, H.M.; Mremal, G.D.; Kansedo, J.; Lee, K.T. Pre-treatment of high free fatty acids oils by chemical re-esterification for biodiesel production-A review. J. Adv. Chem. Engineer. Sci. 2013, 3, 242-247, https://doi.org/10.4236/aces.2013.34031.

16. Vardon, D.R.; Moser, B.R.; Zheng, W.; Witkin, K.; Evangelista, R.L.; Strathmann, T.J.; Rajagopalan, K.; Sharma, B.K. Complete utilization of spent coffee grounds to produce biodiesel, bio-oil, and biochar. J. ACS Sustainable Chem. Eng. 2013, 1, 1286-1294, https://doi.org/10.1021/sc400145w.

17. Wang, Y.; Ou, S.; Liu, P.; Zhang, Z. Preparation of biodiesel from waste cooking oil via two-step catalyzed process. J. Energ. Convers. Manage. 2007, 48, 184-188, https://doi.org/10.1016/j.enconman.2006.04.016.

18. Jansri, S. Preparation of vegetable oil as biodiesel feedstock via re-esterification: A suitable catalyst. $J$. Energy Procedia 2015, 79, 143-148, https://doi.org/10.1016/j.egypro.2015.11.451.

19. AOCS. Official Methods \& Recommended Practices. 4th ed.; American Oil Chemists Society: USA, 1993.

20. Cai, Z.Z.; Wang, Y.; Teng, Y.L.; Chong, K.M.; Wang, J.W.; Zhang, J.W.; Yang, D.P. A two-step biodiesel production process from waste cooking oil via recycling crude glycerol esterification catalyzed by alkali catalyst. J. Fuel. Process. Technol. 2015, 137, 186-193, https://doi.org/10.1016/j.fuproc.2015.04.017.

21. Kumar, V.; Muthuraj, M.; Palabhanvi, B.; Kumar, A.; Das, D. Evaluation and optimization of two stage sequential in situ transesterification process for fatty acid methyl ester quantification from microalgae. $J$. Renew. Energy. 2014, 68, 560-569, https://doi.org/10.1016/j.renene.2014.02.037. 